\title{
PRELIMINARY RESULTS OF REVISIONS OF SOIL MAPS FOR AGRICULTURAL LANDS OF THE REPUBLIC OF BASHKORTOSTAN
}

\author{
Key words: soil maps revision; field surveys; digital map plotting; soil fertility; land monitoring.
}

\section{Authors' personal details}

1. Marat Ishbulatov, Candidate of Agricultural Sciences, Head of the Department of Real Estate Cadastre and Geodesy, Federal State Budgetary Educational Institution of Higher Education «Bashkir State Agrarian University», 450001, Ufa, 50-letiya Oktyabrya St., 34, e-mail: img63@mail.ru.

2. Radik Mindibaev, Doctor of Agricultural Sciences, Professor of the Department of Real Estate Cadastre and Geodesy, Federal State Budgetary Educational Institution of Higher Education «Bashkir State Agrarian University», 450001, Ufa, 50-letiya Oktyabrya St., 34, e-mail: mindibaev.ra@yandex.ru.

3. Ilnur Miftakhov, head of the laboratory of the Department of Real Estate Cadastre and Geodesy, Federal State Budgetary Educational Institution of Higher Education «Bashkir State Agrarian University», 450001, Ufa, 50-letiya Oktyabrya St., 34, e-mail: ugt-ufa@bk.ru.

The paper summarizes the preliminary results of the soil survey, revision of the soil maps plotted in the 70-80ies of the past century, and plotting procedures of digital soil maps for agricultural lands in several municipal districts of the Republic of Bashkortostan. The paper described the following stages: selection and preparation of graphic and analytical materials based on the results of previously performed surveys, fieldwork, revision, and plotting of a digital soil map. The study revealed that the area of thick high-humus lands decreased by 7,738 ha, and the area of medium-humus soils fell by 5,374 ha in the Ufa region. The decline is associated with a lot of construction works and designation of the lands for gardening purposes. Chishminsky, Karmaskalinsky, Iglinsky, and Birsky districts are engaged in effective farming practices but do not reach their full potential. There are abandoned arable fields, crop rotations are disrupted, and sunflower growing prevails in crop

(С) Ишбулатов М.Г., Миндибаев Р.А., Мифтахов И.Р. growing practices. Secondary forest growth, a decrease in the humus horizon, and erosion processes are observed in all districts. Aurgazinsky district provides an example of proper land use. The district's agricultural lands are used efficiently, and for their designated purpose, crop rotation guidelines are followed, and agrotechnical requirements are met, and fertilizers are timely applied. The area of thick chernozems increased by 1,889 ha, and the area of medium-humus chernozems rose by 7,415 ha. Askinsky district has almost wholly stopped farming practices, and the lands are being heavily covered with forest. As a result, a slowdown in erosion processes and a natural restoration of soil fertility are observed: highhumus soils increased by $30 \%$, thick soils increased by 4,4 , and medium-thick soils rose by 37,8 thousand hectares in comparison with 1997. Thus, the districts of the republic employ different approaches to agricultural land management.

УДК 663.252.1

DOI: $10.31563 / 1684-7628-2020-56-4-47-54$

О.Ю. Калужина, А.Р. Нафикова, А.Ю. Бодров, Н.Ю. Старцева,

Е.Н. Черненков, Т.В. Арцышевич, А.В. Полюдов

ТЕХНОЛОГИЧЕСКАЯ ХАРАКТЕРИСТИКА СОРТОВ ВИНОГРАДА СЕЛЕКЦИИ БАШКОРТОСТАНА

Ключевые слова: Vitis vinífera; виноград; сорт Карагай; сорт Башкирский; сорт Находка Стреляева; виноградная лоза; виноградная гроздь.

Введение. Виноград - это древнейшая культура, ягоды которой обладают хорошими вкусовыми качествами и высокой пищевой ценностью. В нем содержатся сахара, пектин, органи- ческие кислоты, белковые вещества и различные витамины. По данным Минсельхоза России, на 1 октября 2020 года заложено 2,4 тыс. га виноградников, а валовой сбор винограда составил 
345 тыс. т. За первые 8 месяцев 2020 года произведено 42,4 млн дал винодельческой продукции, в том числе 20 млн дал тихих и 7,3 млн дал игристых вин [6]. Промышленным возделыванием винограда занимаются специализированные хозяйства в Краснодарском и Ставропольском краях, Республике Дагестан, Кабардино-Балкарской и Чеченской Республиках, Крыму и Ростовской области [4].

В ряде регионов, которые не являются традиционными для возделывания винограда, исследователи проводят хозяйственно-биологическую и технологическую оценки различных местных сортов винограда и изучают их пригодность для виноделия. Например, исследователи Алтайского края провели оценку качества десяти образцов винных напитков из красных сортов винограда (урожай 2008-2012 гг.), культивируемых в Алтайском крае. Обосновали применение технологии плодового виноделия при производстве винных напитков. Исследования показали, что все винные напитки имеют высокое качество и отвечают требованиям ГОСТ Р 52523-2006 и ГОСТ Р 51159-2009, также отмечено, что винные напитки из сортов винограда Зилга, Память Домбковской и Таежный отличаются высоким и стабильным качеством. Эти сорта можно рекомендовать для производства натуральных столовых полусладких и сухих вин $[1,2]$.

В Республике Башкортостан в личных подсобных хозяйствах возделывается большое количество интродуцированных сортов, различающихся по срокам созревания, вкусовым достоинствам, устойчивости к фитопатогенам и вредителям, а также зимостойкости $[7,9,10]$. Исследователями Башкирского ГАУ ранее были изучены возможности изготовления вина в Республике Башкортостан из четырех сортов винограда: Александр, Изабелла, Башкирский и Юбилейный. Анализ полученных вин показал, что вина из сортов Александр и Изабелла по сравнению с продуктами из винограда сортов Башкирский и Юбилейный характеризовались более полным и ярким вкусом, насыщенным цветом [5]. Виноград является южным растением, но благодаря лианообразному стеблю его возможно возделывать в условиях Республики Башкортостан в укрывной культуре. С 30-х годов прошлого столетия работами по изучению особенностей роста винограда в Башкортостане занималась Л.Н. Стреляева. В результате ее многолетних исследований были созданы новые сорта винограда селекции Башкортостана, включенные в государственный реестр селекционных достижений по регионам РФ. Имеются патенты на данные сорта [10]. Среди них выделены следующие винные сорта винограда: Кара- гай, Башкирский, Находка Стреляева. Для посадки подходят возвышенные солнечные участки, без сквозняков, с кислой почвой. В Республике Башкортостан посадку винограда рекомендуют осуществлять весной, примерно в конце мая, в посадочные ямы с водой, глиной и перегноем [3].

Целью данной работы является изучение биологических особенностей и технологических характеристик сортов винограда селекции Башкортостана.

В качестве объектов исследования были выбраны сорта винограда, включенные в государственный реестр селекционных достижений по регионам РФ: Карагай, Башкирский, Находка Стреляева. Данные сорта при укрытии выдерживают температуру минус $30-40{ }^{\circ} \mathrm{C}$. Для сравнения были изучены сорта винограда Альфа дальневосточная и Амурский, районированные в Приморском крае. Все сорта винограда выращены в 2020 году в условиях Республики Башкортостан в Кушнаренковском селекционном центре ФГБНУ УФИЦ РАН БНИИСХ (рисунок 1), который находится в пределах Прибельской увалисто-волнистой равнины, в переходной лесостепной зоне. Ниже представлена краткая характеристика исследуемых сортов.

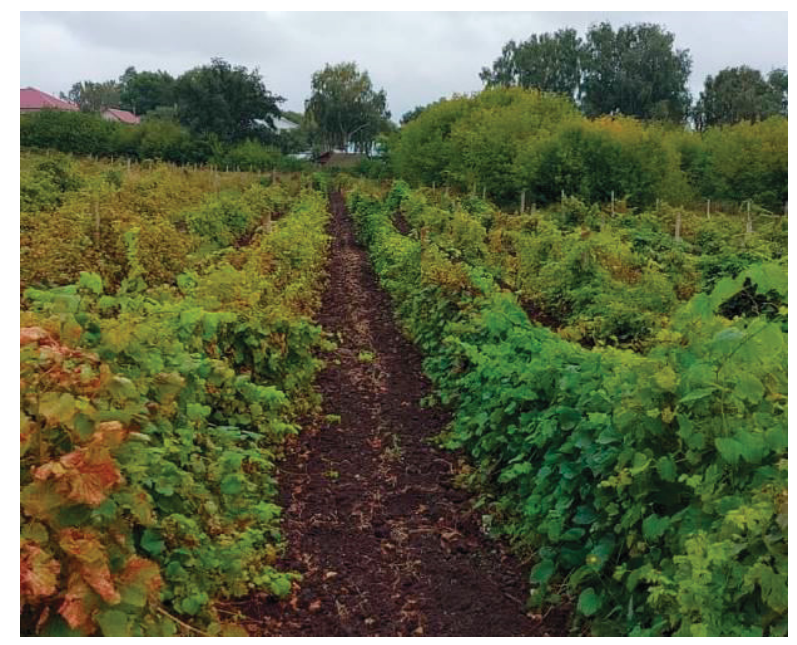

Рисунок 1

Виноградник Кушнаренковского селекционного центра по плодово-ягодным культурам и винограду (сентябрь 2020 г.)

Kapazaй. Сорт выделяется высокой морозостойкостью. Урожайность до 6 кг с куста. Гроздь средней массой 90 г, конической формы. Ягоды черные, округлые, мелкие. Содержание сахаров $14 \%$.

Башкирский. Сорт раннего срока созревания. Зимостойкость высокая, урожай $-6-8$ кг с куста. Гроздь среднего размера, рыхлая, средняя масса от 70 до 120 г. Ягоды темно-синие с восковым налетом, округлые. Средняя масса ягоды 1,9 г. Содержание сахаров $16 \%$. 


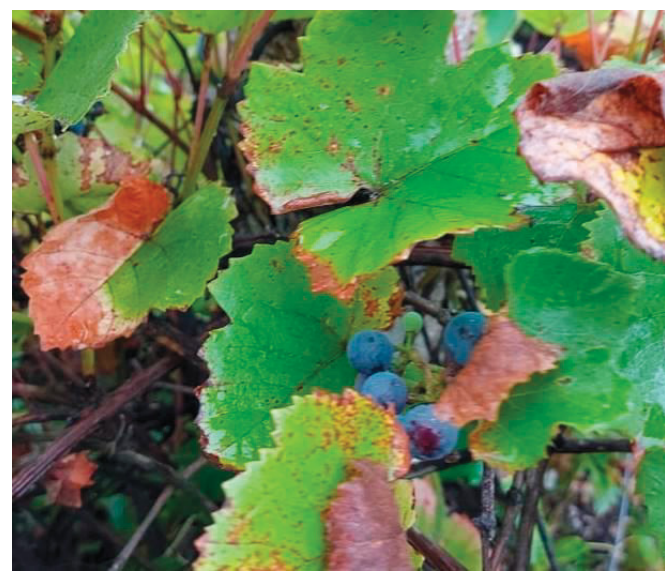

Рисунок 2

Лоза и виноград сорта Карагай (урожай 2020 г.)

Находка Стреляева. Сорт среднераннего срока созревания. Зимостойкость высокая, урожай - 6-8 кг с куста. Куст сильнорослый. Гроздь среднего размера - 100 г. Ягоды темно-синего цвета массой 1,9 г, содержание сахаров - 16,5 \%.

Альфа дальневосточная. Селекция «Ламбруска» и «Рипария». Хорошая урожайность, морозоустойчивость. Масса грозди - 150-180 г.

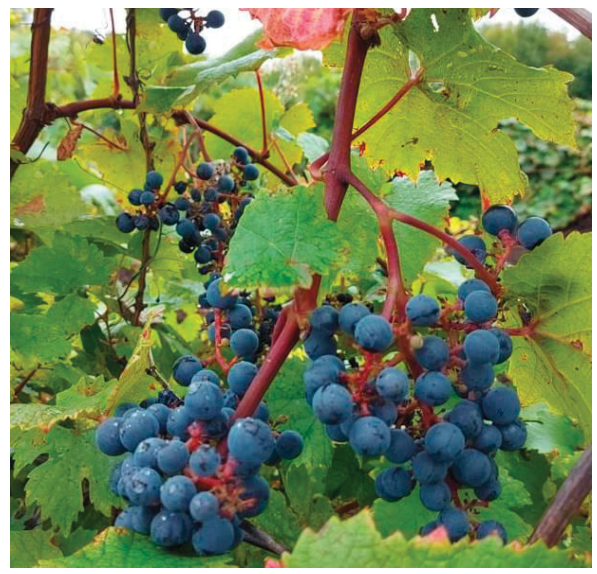

Рисунок 4

Лоза и виноград сорта Находка Стреляева (урожай 2020 г.)

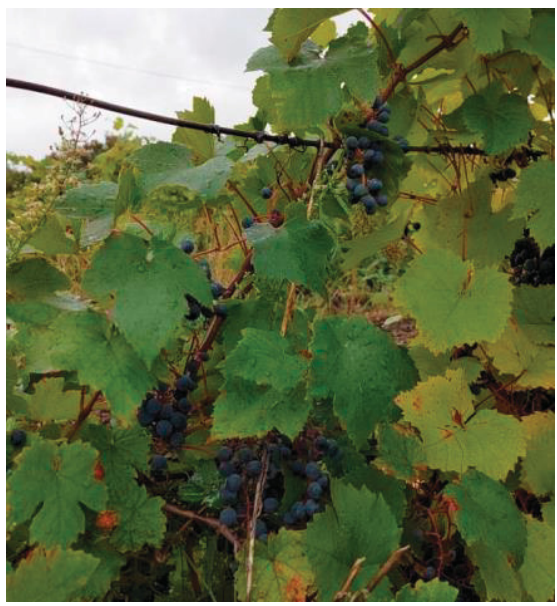

Рисунок 6

Лоза и виноград сорта Амурский (урожай 2020 г.)

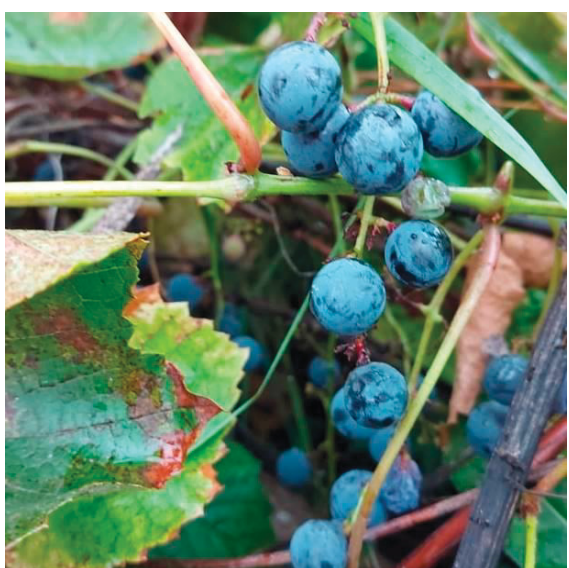

Рисунок 3

Лоза и виноград сорта Башкирский (урожай 2020 г.)

Урожайность - 10-14 кг с куста. Ягоды округлой формы, массой 2-3 г. Кислотность 10-11 г/л. Содержание сахаров $15-18 \%$.

Амурский. Грозди слегка конической формы с неплотно расположенными ягодами, рыхлые. Ягоды имеют фиолетовый окрас с синим налетом. Диаметр ягод до 1,2 см. Содержание сахаров $14 \%$.

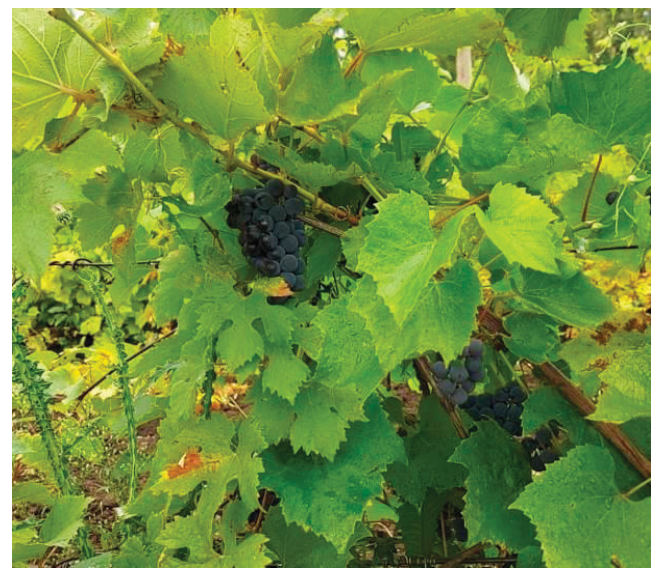

Рисунок 5

Лоза и виноград сорта Альфа (урожай 2020 г.)

Виноград собирали ручным способом на стадии технологической зрелости и анализировали на соответствие требованиям к винограду для выработки винодельческой продукции, указанным в ГОСТ 31782-2012 Виноград свежий машинной и ручной уборки для промышленной переработки. Технические условия. Массовую концентрацию сахаров определяли в сусле рефрактометрическим методом по ГОСТ 27198-87 (СТ СЭВ 5622-86) Виноград свежий. Методы определения массовой концентрации сахаров.

Результаты анализов представлены в таблице 1 .

Из таблицы 1 видно, что все сорта винограда соответствуют требованиям ГОСТ 31782-2012, предъявляемым к винограду ручной уборки для 
выработки винодельческой продукции по органолептическим показателям, а также по показателям, характеризующим качество уборки и транспортирования. Количество ягод, поврежденных болезнями и вредителями, не превышает стандартных значений. Исследуемые сорта винограда отличаются по сахаристости, которая также зависит от погодно-климатических условий произрастания. Массовая концентрация сахаров в сусле из сортов винограда Альфа дальневосточная, Амурский, Башкирский и Карагай колеблется от 14,3 до 16,7 г/100 cм ${ }^{3}$, что меньше соответствующего стандартного показателя для винограда, предназначенного для выработки красных виноматериалов. Сорт винограда Находка Стреляева отличается самой высокой массовой концентрацией сахаров в сусле, которая составляет 17,3 г/100 $\mathrm{cm}^{3}$ и удовлетворяет требованиям ГОСТ 31782-2012.

Кроме изучения сортов винограда на соответствие требованиям действующего стандарта, также проводилась характеристика ряда показателей, не нормируемых ГОСТ 31782-2012, но важных с технологической точки зрения Результаты анализа этих показателей приведены в таблице 2.

Таблица 1 Органолептические и физико-химические показатели различных сортов винограда урожая 2020 г. на соответствие требованиям ГОСТ 31782-2012

\begin{tabular}{|c|c|}
\hline \multicolumn{2}{|r|}{$\begin{array}{c}\text { Наименование показателя и его характеристика для винограда ручной уборки } \\
\text { для выработки винодельческой продукции }\end{array}$} \\
\hline \multicolumn{2}{|r|}{ Внешний вид } \\
\hline Требования стандарта & Чистые, свежие, здоровые грозди одного ампелографического сорта \\
\hline Альфа дальневосточная & Гроздь обладает средней плотностью, ягоды округлой формы, с достаточно плотным восковым налетом \\
\hline Амурский & Гроздь конической формы с неплотно расположенными ягодами. Ягоды среднего размера \\
\hline Башкирский & Гроздь целая, среднего размера, ветвистой формы. Ягоды крупные, округлые \\
\hline Находка Стреляева & Гроздь среднего размера, форма ягод овальная, ягоды не крупные \\
\hline Карагай & Гроздь крупная, ягоды плотно прилегают друг к другу. Ягоды крупные \\
\hline \multicolumn{2}{|r|}{ Вкус и запах } \\
\hline Требования стандарта & $\begin{array}{c}\text { Характерный для данного ампелографического сорта в стадии технической зрелости, } \\
\text { без постороннего запаха и/или привкуса }\end{array}$ \\
\hline Альфа дальневосточная & Приятная сладость, без кислинки и постороннего запаха \\
\hline Амурский & Выраженная сладость с хорошей кислинкой, без постороннего привкуса \\
\hline Башкирский & Приятная сладость с небольшой кислинкой, без постороннего привкуса \\
\hline Находка Стреляева & Хорошо выраженная сладость со слабой кислинкой, медовый запах \\
\hline Карагай & Приятная сладость с выраженной кислинкой \\
\hline \multicolumn{2}{|r|}{ Массовая концентрация сахаров, г/100 см³, не менее } \\
\hline Требования стандарта & 17,0 для красных \\
\hline Альфа дальневосточная & 14,3 \\
\hline Амурский & 16,7 \\
\hline Башкирский & 14,8 \\
\hline Находка Стреляева & 17,3 \\
\hline Карагай & 15,1 \\
\hline \multicolumn{2}{|r|}{$\begin{array}{c}\text { Примесь других ампелографических сортов, соответствующих } \\
\text { по ботаническому виду и окраске ягод основному сорту, \%, не более }\end{array}$} \\
\hline Требования стандарта & 15 \\
\hline Альфа дальневосточная & \multirow{5}{*}{ Не обнаружено } \\
\hline Амурский & \\
\hline Башкирский & \\
\hline Находка Стреляева & \\
\hline Карагай & \\
\hline \multicolumn{2}{|r|}{$\begin{array}{l}\text { Примесь других ампелографических сортов, не соответствующих } \\
\text { по ботаническому виду и окраске ягод основному сорту, \%, не более }\end{array}$} \\
\hline Требования стандарта & Не допускается \\
\hline Альфа дальневосточная & \multirow{5}{*}{ Отсутствуют } \\
\hline Амурский & \\
\hline Башкирский & \\
\hline Находка Стреляева & \\
\hline Карагай & \\
\hline \multicolumn{2}{|r|}{ Массовая доля раздавленных ягод, \%, не более } \\
\hline Требования стандарта & 20 \\
\hline Альфа дальневосточная & 5 \\
\hline Амурский & 5 \\
\hline Башкирский & 6 \\
\hline Находка Стреляева & 4 \\
\hline Карагай & 7 \\
\hline
\end{tabular}




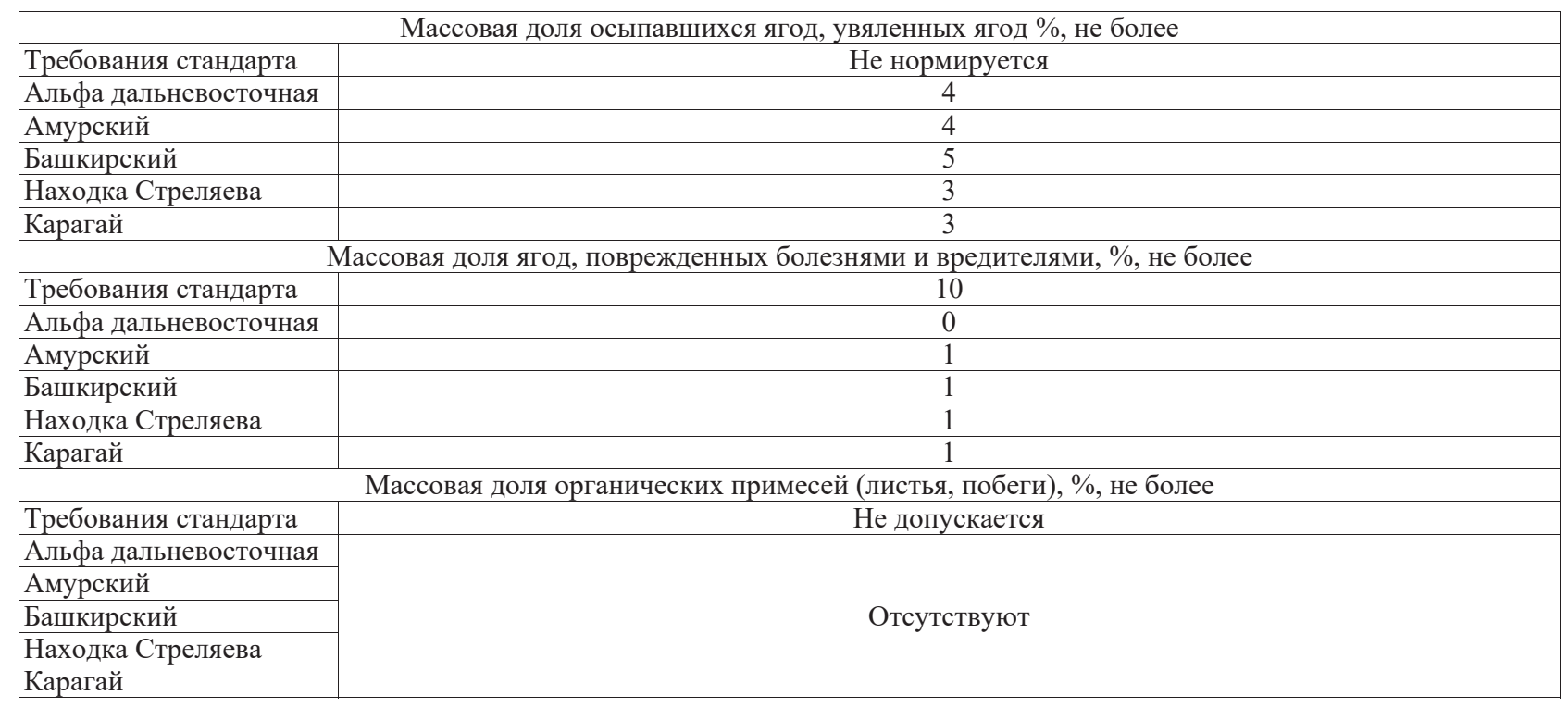

Таблица 2 Характеристика сортов винограда урожая 2020 г. по технологическим показателям, не нормируемым в ГОСТ 31782-2012

\begin{tabular}{|l|c|c|c|c|c|}
\hline \multirow{2}{*}{\multicolumn{1}{|c|}{ Наименование показателя }} & \multicolumn{5}{|c|}{ Сорт винограда } \\
\cline { 2 - 6 } & $\begin{array}{c}\text { Альфа дальне- } \\
\text { восточная }\end{array}$ & Амурский & Карагай & $\begin{array}{c}\text { Находка } \\
\text { Стреляева }\end{array}$ & Башкирский \\
\hline Массовая доля нецелых гроздей, \% & 9,8 & 5,5 & 9,9 & 5,5 & 9,8 \\
\hline Масса грозди, г & 93 & 98 & 88 & 75 & 83 \\
\hline Массовая доля влаги в ягодах, \% & 80,3 & 80,6 & 84,3 & 75,3 & 82,5 \\
\hline $\begin{array}{l}\text { Массовая доля растворимых сухих веществ } \\
\text { (общий экстракт) в свежем сырье, \% }\end{array}$ & 10,0 & 10,0 & 6,2 & 19,0 & 6,0 \\
\hline $\begin{array}{l}\text { Массовая доля нерастворимых сухих веществ } \\
\text { (общий экстракт) в свежем сырье, \% }\end{array}$ & 9,7 & 9,4 & 9,5 & 5,7 & 11,5 \\
\hline Массовая доля золы, \% & 5,2 & 6,5 & 4,3 & 4,1 & 3,5 \\
\hline
\end{tabular}

В исследуемых сортах массовая доля нецелых гроздей находится в пределах от 5,5 до $9,9 \%$. Наименьшая масса грозди у сорта Находка Стреляева - 75 г. Наибольшая масса у сорта Амурский - 98 г. При этом, согласно сортовой характеристике, масса грозди винограда сорта Амурский составляет 250 г, а при усиленной агротехнике может достигать 500 г в условиях умеренного муссонного климата Приморского края. Но в континентальном климате Республики Башкортостан масса грозди сорта Амурский существенно меньше. При изучении характеристик ягод установили, что виноград сорта Находка Стреляева содержит наибольшее количество сухих веществ, имеет наименьшую влажность, массовая доля влаги составила $75,3 \%$, в то время как в остальных сортах этот показатель варьирует в пределах 80,3-84,3 \%.
Также сорт Находка Стреляева отличается высоким выходом растворимых экстрактивных веществ - $19 \%$ к массе ягод. Содержание кислот является одним из важнейших показателей качества сырья и характеризует степень свежести ягод. В винограде эти колебания зависят от сорта, зрелости, климатических условий, уровня агротехники и других факторов. Лучшие результаты даст вино из сортов винограда с более высоким содержанием органических кислот, среди которых преобладает винная. Был проведен сравнительный анализ исследуемых сортов по содержанию кислот в урожае 2018-2020 гг. Массовая концентрация титруемых кислот в пересчете на винную кислоту определяли по ГОСТ 25555.0-82 Продукты переработки плодов и овощей. Методы определения титруемой кислотности. Результаты анализа представлены в таблице 3 .

Таблица 3 Массовая доля кислот в пересчете на винную кислоту, \%, в ягодах винограда урожая 2018-2020 гг.

\begin{tabular}{|c|c|c|c|c|c|c|}
\hline \multirow[b]{2}{*}{ Год } & \multirow{2}{*}{$\begin{array}{c}\text { Количество с мая по сентябрь: } \\
\text { солнечных дней / средняя температура } \\
\text { воздуха }{ }^{\circ} \mathrm{C} / \text { дней осадков }\end{array}$} & \multicolumn{5}{|c|}{ Сорт винограда } \\
\hline & & Амурский & $\begin{array}{l}\text { Альфа даль- } \\
\text { невосточная }\end{array}$ & Башкирский & $\begin{array}{c}\text { Находка } \\
\text { Стреляева }\end{array}$ & Карагай \\
\hline 2018 & $42 / 20,8 / 30$ & 0,76 & 0,27 & 0,60 & 0,40 & 0,78 \\
\hline 2019 & $23 / 19,8 / 33$ & 0,78 & 0,28 & 0,63 & 0,39 & 0,77 \\
\hline 2020 & $44 / 20,9 / 30$ & 0,76 & 0,29 & 0,62 & 0,39 & 0,79 \\
\hline
\end{tabular}


По данным таблицы 3 видно, что содержание кислот в ягодах винограда исследуемых сортов мало зависит от метеорологических условий года. Наименьшей кислотностью характеризуется сорт Альфа дальневосточная, сорта Башкирский, Карагай и Амурский обладают высоким содержанием кислот, сорт Находка Стреляева имеет умеренную кислотность.
Таким образом, климатические условия Республики Башкортостан позволяют получать урожай винограда местных и интродуцированных сортов с различными физико-химическими и органолептическими показателями. Из исследованных пяти сортов винограда сорт Находка Стреляева по своим технологическим характеристикам наиболее пригоден для выработки винодельческой продукции.

\section{Библиографический список}

1. Апарнева, М.А. Качество винных напитков из красных сортов винограда Алтайского края [Текст] / М.А. Апарнева, В.П. Севодин // Техника и технология пищевых производств. 2013. № 4. C. 201-203.

2. Дергунов, А.В. Влияние сортовых особенностей винограда и природы спиртующего агента на качество ликерных вин [Текст] / А.В. Дергунов // Политематический сетевой электронный научный журнал Кубанского государственного аграрного университета. 2017. № 2.

3. Абдеева, М.Г. Плодово-ягодные культуры в Республике Башкортостан [Текст] / В.М. Шириева Т.Г. Демина, Р.А. Шафиков // РАСХН, ГНУ Башкирский НИИСХ. Уфа, 2012. 174 с.

4. Зармаев, А.А. Виноградарство с основами первичной переработки винограда [Текст] / А.А. Зармаев. Изд. 2-е, доп., перераб. М.-СПб: Лань, 2015. 215 с.

5. Калужина, О.Ю. Вино из башкирских сортов винограда [Текст] / О.Ю. Калужина, Е.И. Кощина, К.С. Яковлева // Состояние и перспективы увеличения производства высококачественной продукции сельского хозяйства. Материалы I совместной с институтом животноводства Таджикской академии сельскохозяйственных наук Международной научно-практической конференции, 23-25 ноября 2017 г. Уфа, 2017.
6. К 1 октября в России собрано 345 тыс. т винограда [Электронный ресурс] // Центр Агроаналитики. 5 октября 2020 г. Режим доступа: https://specagro.ru/news/202010/k-1-oktyabrya-vrossii-sobrano-345-tys-t-vinograda.

7. Габдуллина, 3.3. Разработка рецептуры газированного винного напитка с добавлением экстракта шиповника и клубники [Текст] / 3.3. Габдуллина, А.Н. Гусев // Молодой исследователь: вызовы и перспективы: сборник статей по материалам LXXI международной научнопрактической конференции. 2018. С. 228-232.

8. Габдуллина, 3.3. Влияние экстрактов шиповника и клубники на содержание кислот в винных напитках [Текст] / 3.3. Габдуллина, А.Н. Гусев // Молодой исследователь: вызовы и перспективы. Сборник статей по материалам LXXII международной научно-практической конференции. 2018. С. 477-480.

9. Шафиков, Р.А. Виноград Vitus L. «Карагай» [Текст] / Р.А. Шафиков, Л.Н. Стреляева, Н.В. Майстренко // Патент на селекционное достижение RU 5903. Заявка № 9252935 от 07.11. 2007.

10. Старцева, Н.Ю. Селекция винограда в Республике Башкортостан [Текст] / Н.Ю. Старцева, Р.А. Шафиков // Известия Уфимского научного центра РАН. 2018. № 3-6. С. 47-50.

\section{Сведения об авторах}

1. Калужина Олеся Юрьевна, ORCID 0000-0001-5923-1231, кандидат технических наук, доцент, заведующий кафедрой технологии общественного питания и переработки растительного сырья, ФГБОУ ВО Башкирский ГАУ, г. Уфа, ул. Хадии Давлетшиной, 6, e-mail: 216322705@mail.ru.

2. Нафикова Айгуль Рашитовна, ORCID 0000-0002-0741-6354, старший преподаватель кафедры технологии общественного питания и переработки растительного сырья, ФГБОУ ВО Башкирский ГАУ, г. Уфа, ул. Хадии Давлетшиной, 6, e-mail: aigoul.nafikova@gmail.com.

3. Бодров Александр Юрьевич, старший преподаватель кафедры технологии общественного питания и переработки растительного сырья, ФГБОУ ВО Башкирский ГАУ, г. Уфа, ул. Хадии Давлетшиной, 6.

4. Старцева Наталья Юрьевна, руководитель Кушнаренковского селекционного центра, ФГБНУ УФИЦ РАН БНИИСХ, с. Кушнаренково, Садовая аллея, 21, e-mail: kuch_oph@mail.ru.

5. Черненков Евгений Николаевич, кандидат сельскохозяйственных наук, доцент кафедры технологии общественного питания и переработки растительного сырья, ФГБОУ ВО Башкирский ГАУ, г. Уфа, ул. Хадии Давлетшиной, 6, e-mail: chernenkov.1990@mail.ru. 
6. Арцышевич Татьяна Владимировна, бакалавр кафедры технологии общественного питания и переработки растительного сырья, ФГБОУ ВО Башкирский ГАУ, г. Уфа, ул. Хадии Давлетшиной, 6 , e-mail: tanya.artsyshevitch@yandex.ru.

7. Полюдов Александр Васильевич, бакалавр кафедры технологии общественного питания и переработки растительного сырья, ФГБОУ ВО Башкирский ГАУ, г. Уфа, ул. Хадии Давлетшиной, 6, e-mail: alexavp18@mail.ru.

Виноград - южное растение, но его возможно возделывать в условиях Республики Башкортостан в укрывной культуре. Для изучения биологических особенностей и технологических характеристик сортов винограда селекции Башкортостана были выбраны сорта Карагай, Башкирский, Находка Стреляева, включенные в государственный реестр селекционных достижений по регионам РФ. В качестве контрольного варианта служили интродуцированные сорта винограда Альфа дальневосточная и Амурский. Все сорта винограда выращены в 2020 году в Кушнаренковском селекционном центре ФГБНУ УФИЦ РАН БНИИСХ. Виноград, собранный на стадии технологической зрелости, анализировали на соответствие требованиям к винограду для винодельческой продукции по ГОСТ 31782-2012 Виноград свежий машинной и ручной уборки для промышленной переработки. Технические условия. Также проводили характеристику ряда показателей, не нормируемых стандартом, но важных с технологической точки зрения. Установлено, что сорт винограда Находка Стреляева среди других исследованных сортов при наименьшей массе грозди 75 г имеет наибольшее содержание растворимых экстрактивных веществ, сахаров - 17,3 г/100 см ${ }^{3}$, обладает умеренным содержанием кислот, не более $0,4 \%$ в пересчете на винную кислоту. Массовая концентрация сахаров в сусле из винограда сортов Карагай, Башкирский, Альфа дальневосточная и Амурский варьирует в пределах от 14,3 до 16,7 г/100 $\mathrm{cm}^{3}$, что меньше соответствующего стандартного показателя для винограда, предназначенного для выработки красных виноматериалов. Виноград сорта Альфа дальневосточная имеет низкое содержание титруемых кислот в пересчете на винную кислоту - не более 0,3 \%, сорта Башкирский, Карагай и Амурский обладают высоким содержанием кислот - 0,6$0,79 \%$. Таким образом, климатические условия Республики Башкортостан позволяют получать урожай винограда местных и интродуцированных сортов с различными физико-химическими и органолептическими показателями. Из исследованных пяти сортов винограда сорт Находка Стреляева по своим технологическим характеристикам наиболее пригоден для виноделия.

O. Kaluzhina, A. Nafikova, A. Bodrov, N. Startseva, E. Chernenkov, T. Artyshevich, A. Polyudov

TECHNOLOGICAL CHARACTERISTICS

OF GRAPE VARIETIES BREEDING BASHKORTOSTAN

Key words: Vitis vinifera; grape; grape varieties Karagay; Bashkir; Nakhodka Strelyayeva; bunch of grapes; vine.

\section{Authors' personal details}

1. Olesya Kaluzhina, ORCID 0000-0001-5923-1231, Candidate of technical sciences, associate professor, head of the Department of Public Catering Technology and Plant Raw Materials Processing, Federal State Budgetary Educational Institution of Higher Education «Bashkir State Agrarian University», e-mail: 216322705@mail.ru.

2. Aigul Nafikova, ORCID 0000-0002-0741-6354, senior lecturer at the Department of Public Catering Technology and Plant Raw Materials Processing, Federal State Budgetary Educational Institution of Higher Education «Bashkir State Agrarian University», 450001, Ufa, st. Hadia Davletshina, 6, e-mail: aigoul.nafikova @gmail.com.

3. Alexander Bodrov, senior lecturer at the Department of Public Catering Technology and Plant Raw Materials Processing, Federal State Budgetary Educational Institution of Higher Education «Bashkir State Agrarian University», 450001, Ufa, st. Hadia Davletshina, 6.

4. Natalya Starzeva, Head of the Kushnarenkovsky Breeding Center, p. Kushnarenkovo, st. Sadovaya Alley, 21, e-mail: kuch_oph@mail.ru.

5. Evgeny Chernenkov, Candidate of agricultural sciences, associate professor of the Department of Public Catering Technology and Plant Raw Materials Processing, Federal State Budgetary Educational Insti- 
tution of Higher Education «Bashkir State Agrarian University», 450001, Ufa, st. Hadia Davletshina, 6, e-mail: chernenkov.1990@mail.ru.

6. Tatyana Artsyshevich, Bachelor of the Department of Public Catering Technology and Plant Raw Materials Processing, Federal State Budgetary Educational Institution of Higher Education «Bashkir State Agrarian University», 450001, Ufa, st. Hadia Davletshina, 6, e-mail: tanya.artsyshevitch@yandex.ru.

7. Alexander Polyudov, Bachelor of the Department of Public Catering Technology and Plant Raw Materials Processing, Federal State Budgetary Educational Institution of Higher Education «Bashkir State Agrarian University», 450001, Ufa, st. Hadia Davletshina, 6, e-mail: alexavp18@mail.ru.

Grapes are a southern plant, but it is possible to cultivate it in the Republic of Bashkortostan conditions in a covering culture. Karagai, Bashkirsky, and Nakhodka Strelyaeva were selected to study the biological features and technological characteristics. The listed varieties are varieties bred in Bashkortostan and are included in the state register of breeding achievements in the Russian Federation regions. Introduced grape varieties Alfa Dalnevostochnaya and Amurskiy served as a control option. All grape varieties were grown in 2020 at the Kushnarenkovsky breeding center of the Bashkir Research Institute of Agriculture. Grapes harvested at the stage of technological maturity were analyzed for compliance with grapes requirements for wine production following GOST 31782-2012 Fresh grape of combine and hand harvesting for industrial processing. Specifications. We also characterized several indicators that are not standardized by the standard but are important from a technological perspective. It was found that the grape variety Nakhodka
Strelyaeva, among other studied varieties, with the smallest bunch weight of $75 \mathrm{~g}$, has the highest content of soluble extractives, sugars $-17,3 \mathrm{~g} / 100 \mathrm{~cm}^{3}$, has a moderate acid content, not more than $0,4 \%$ in terms of tartaric acid. The mass concentration of sugars in the must from the grape varieties Karagai, Bashkirsky, Alfa Dalnevostochnaya, and Amurskiy varies from 14,3 to $16,7 \mathrm{~g} / 100 \mathrm{~cm}^{3}$, which is less than the corresponding standard indicator for grapes intended for the production of red wine materials. The grapes of the Alfa Dalnevostochnaya variety have a low content of titratable acids in tartaric acid - no more than 0,3\%, the Bashkir, Karagai, and Amurskiy varieties have a high acid content - 0,6$0,79 \%$. Thus, the Republic of Bashkortostan's climatic conditions make it possible to obtain a harvest of grapes of local and introduced varieties with various physicochemical and organoleptic characteristics. Of the five grape varieties studied, the Nakhodka Strelyaeva variety is the most suitable for winemaking by its technological characteristics.

(C) Калужина О.Ю., Нафикова А.Р., Бодров А.Ю., Старцева Н.Ю.,

Черненков Е.Н., Арцышевич Т.В., Полюдов А.В.

УДК 664.7

DOI: $10.31563 / 1684-7628-2020-56-4-54-61$

С.А. Леонова, А.Л. Вебер, Л.Р. Мухаметрахимова, О.В. Илларионова

\section{СВОЙСТВА НОВЫХ СЕЛЕКЦИОННЫХ СОРТОВ ЗЕРНОБОБОВЫХ КУЛЬТУР, ОПРЕДЕЛЯЮЩИЕ ВОЗМОЖНОСТЬ ИХ ПЕРЕРАБОТКИ В ПРОДУКТЫ ЗДОРОВОГО ПИТАНИЯ}

\section{Ключевые слова: горох; фасоль; морфометрические характеристики; микроструктура; хими- ческий состав.}

Введение. Зернобобовые культуры являются ценным источником белка, витаминов и микроэлементов, богаты пищевыми волокнами и биологически активными веществами. Ценность бобовых культур состоит не только в высоком содержании белка, но и в его полноценности. Содержание основных незаменимых аминокислот в нем в 1,5-3,0 раза больше, чем в белке злаков.

Белки семян чечевицы и фасоли, как и белки гороха, содержат все незаменимые аминокис- лоты и являются биологически полноценными. Наибольшее количество незаменимых аминокислот - 38,4\% - накапливается в семенах фасоли при $32,8 \%$ у чечевицы и $33,7 \%$ у гороха. В ней имеется большое количество калия и фосфора, меди и цинка. Белки фасоли богаче серосодержащими аминокислотами (метионином), а также триптофаном, фенилаланином, валином, лейцином и изолейцином $[1,2]$. Доля незаменимых аминокислот в общем аминокислотном составе выше у фасоли (38 \%) и гороха (37\%). У 